\title{
Skin cancer development in a birthmark
}

\author{
Alexandra C. Finstad BSc, Mark G. Kirchhof MD PhD
}

Cite as: CMAJ 2019 September 30;191:E1082. doi: 10.1503/cmaj.190492

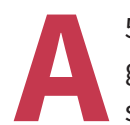

57-year-old man presented with concerns about a new growth on his scalp. He was born with a birthmark on his scalp that had become bumpy over time, but over the previous year he had noticed the development of a new nodule. He had no personal or family history of skin cancer nor any history of severe sunburns or tanning bed use. He reported no regular use of medications and had no history of medical problems. Physical examination showed a pink and grey nodule within a verrucous plaque (Figure 1). Biopsy was performed and showed a pigmented basal cell carcinoma within a nevus sebaceus.

Nevus sebaceus is a cutaneous hamartoma that occurs in less than $1 \%$ of the population, most often on the face and scalp..$^{1-3}$ It classically presents as a waxy, skin-colored to yellow-orange alopecic plaque. These lesions proportionally enlarge with age and undergo proliferative changes at puberty, commonly transforming into a verrucous or cerebriform plaque (see Appendix 1, available at www.cmaj.ca/lookup/suppl/doi:10.1503/cmaj.190492/-/DC1, for normal nevus sebaceus images). ${ }^{2}$ Although it usually presents at birth, nevus sebaceus may not be identified until later in life.

Secondary neoplasms develop within nevus sebaceus in about $15 \%-21.4 \%$ of cases. ${ }^{1,2}$ These secondary neoplasms are benign in about $13.6 \%-18.9 \%$ of cases and include trichoblastomas, syringocystadenomas papillifera, trichilemmomas, sebaceomas, and apocrine or eccrine adenomas. ${ }^{1,2}$ Malignant transformation is uncommon, occurring in $0.8 \%-2.5 \%$ of secondary neoplasms. ${ }^{1,2}$ Basal cell carcinoma is the most commonly associated malignant disorder, with others being squamous cell carcinoma and sebaceous carcinoma. ${ }^{1,2}$

Management of nevus sebaceus should be decided on a caseby-case basis. As malignant transformation is rare, especially in children, observation should be the standard of care until adolescence. ${ }^{1-3}$ In adolescence, the need for prophylactic excision should be evaluated for preventive and cosmetic reasons. ${ }^{1-3}$ Ultimately, the timing and need for excision should be decided on by the physician, patient and family. ${ }^{3}$

\section{References}

1. Cribier B, Scrivener $Y$, Grosshans E. Tumors arising in nevus sebaceus: a study of 596 cases. J Am Acad Dermatol 2000;42:263-8.

2. Idriss MH, Elston DM. Secondary neoplasms associated with nevus sebaceus of Jadassohn: a study of 707 cases. J Am Acad Dermatol 2014;70:332-7.

3. Rosen H, Schmidt B, Lam HP, et al. Management of nevus sebaceous and the risk of basal cell carcinoma: an 18-year review. Pediatr Dermatol 2009;26:676-81.

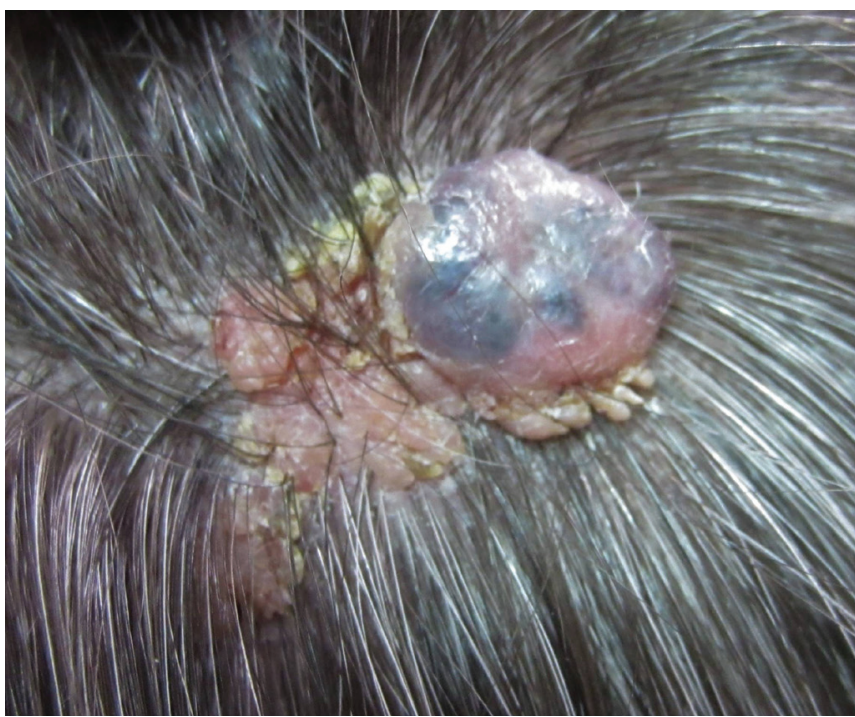

Figure 1: A pink and grey shiny nodule within a verrucous plaque on the scalp of a 57-year-old man. Histopathological examination identified a pigmented basal cell carcinoma within a nevus sebaceus.

Competing interests: None declared.

This article has been peer reviewed.

The authors have obtained patient consent.

Affiliations: Faculty of Medicine (Finstad) and Division of Dermatology (Kirchhof), Department of Medicine, University of Ottawa; Ottawa Hospital (Kirchhof), Ottawa, Ont.

Acknowledgement: The authors thank Richard Haber and Nordau Kanigsberg for providing the normal nevus sebaceus images in Appendix 1.

Correspondence to: Mark Kirchhof, mkirchho@uottawa.ca

Clinical images are chosen because they are particularly intriguing, classic or dramatic. Submissions of clear, appropriately labelled highresolution images must be accompanied by a figure caption. A brief explanation (300 words maximum) of the educational importance of the images with minimal references is required. The patient's written consent for publication must be obtained before submission. 